\title{
Low-Splice Loss Design of DS and DF Single-Mode Fibers
}

\author{
Dr C M Jadhao \\ Principal, Mauli College of Engineering, Shegaon- 444203, India
}

\begin{abstract}
The Wavelength of zero first order chromatic dispersion can be shifted to the lowest loss wavelength for silicon fibers at 1.55 um to provide both low dispersion and low loss fiber. Dispersion-Shifted Single Mode Fiber achieves this. However, the design flexibility required to obtain particular dispersion, attenuation, and MFD, bend and Splice Loss characteristics has resulted in specific profile. An alternative modification of the dispersion characteristics of Single Mode Fiber involves the achievement of low dispersion window over the low loss wavelength region and allow flexible WDM i.e. Dispersion-Flattened Single Mode Fiber. The comparison of Splice Loss sensitivities of Dispersion-Shifted and Dispersion-Flattened Single Mode Fiber is analyzed. Since Splices are highly tolerant for longitudinal separation, transverse offset and angular tilt are considered. The comparative analysis shows that these losses are steady in Dispersion-Flattened Single Mode
\end{abstract}

Keywords: Single-Mode Fiber, Slice losses, DSF, DFF

\section{Splice Losses}

Optical fibers are drawn from preforms and hence, at a time only a limited length of fiber can be drawn; this could be several kilometers. However, in a communication system, much longer lengths of continuous fiber may be required and it may become necessary to splice two fibers. Further, in case of break accidental or intentional damage, the fibers have to spliced are together. If the two fibers to be spliced are identical and if they are perfectly aligned, then, in principle, no loss may occur. However, the dimensions, particularly of SMF, are extremely small and some misalignments are unavoidable which result in loss of power. Therefore, it is important to estimate these splice losses for a fiber. The splicing technique is subject to certain conditions, which can cause various amounts of optical power loss at the joint. These losses depend on parameters such as input power distribution to the joint, the length of the fiber between the optical source and the joint, the geometrical and waveguide characteristics of the two fiber ends at the joint, and the fiber and-face qualities.

\subsection{Types of Splicing Losses or Errors}

The splicing errors are mainly caused by mechanical imperfections and mismatching of fiber parameters. Due to the mechanical imperfections or extrinsic losses, these types of errors or losses occur as Transverse Offset, Longitudinal Offset, Angular Misalignment or Tilt, Mismatching mode size.

\section{Simulation of Coupling Loss of Single Mode Fiber}

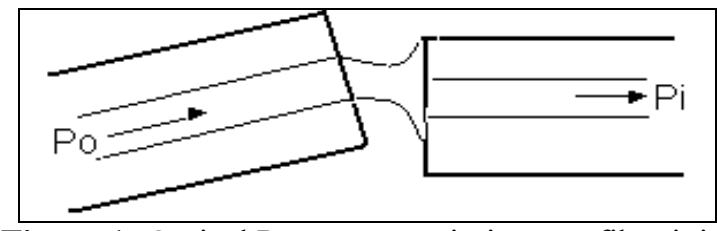

Figure 1: Optical Power transmission at a fiber joint
An ideal joint between two identical optical fibers should completely restore the optical continuity of the guiding medium, so as not to reduce system performance and reliability. Actual joints, however, always suffer from imperfections, resulting in a reduction of power transmitted across the joint. If $\mathrm{P}_{0}$ and $\mathrm{P}_{1}$ are respectively, the coreguided power before and after the joint the coupling efficiency $\eta$ of the joint is

$$
\eta=P_{1} / P_{0}
$$

And the fraction of power $\mathrm{p}$, which lost, is

$\mathrm{P}=\mathrm{P}_{0}-\mathrm{P}_{1} / \mathrm{P}_{0}$

$\mathrm{P}=1-\eta$

The Corresponding coupling loss $\mathrm{L}$ in decibels is given by

$$
\mathrm{L}=-10 \log \eta
$$

Equation (2) is the main parameter that determines the quality of fiber joints. Single mode fibers are more sensitive to alignment errors because of smaller size of waveguide core. An exact evaluation of coupling losses for arbitrary index profile can be performed by numerical techniques ${ }^{1}$ and equation is obtained when the field distribution within the fiber is approximated by Gaussian function ${ }^{2}$

$$
E(r)=E_{0} e^{-r 2 / w 2}
$$

$\mathrm{E}_{0}=$ Field at zero radius

$\mathrm{r}=$ radial co-ordinate or radius

$\mathrm{W}_{0}=$ appropriate half width parameter or width of electric field distribution.

The best match between guassian and exact field.

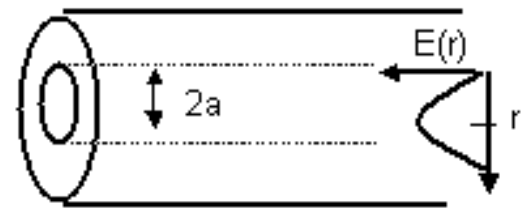

Figure 2: (a) Distribution of light in a SMF 


\section{International Journal of Science and Research (IJSR) \\ ISSN (Online): 2319-7064}

Index Copernicus Value (2013): 6.14 | Impact Factor (2014): 5.611

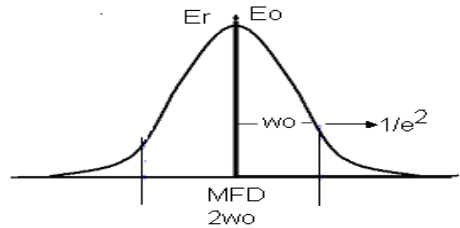

Figure 2: (b) Guassian distribution and MFD

For step-index profiles and LP $(01)$ modes is presented by D. Marcuse $^{3}$. When w satisfies the relationship for step-index fibers

$$
\frac{w}{a}=0.65+\frac{1.6419}{v^{2 / 3}}+\frac{2.879}{v^{6}}
$$

Where $\mathrm{a}=$ core radius

$\mathrm{v}=$ normalized frequency $\left(\mathrm{v}=2 \pi \mathrm{a} / \lambda\left(\mathrm{n}_{1}{ }^{2}-\mathrm{n}_{2}^{2}\right)^{1 / 2}\right.$

For parabolic-index fiber,

$$
\frac{w}{a}=\frac{\sqrt{2}}{v}+\frac{0.23}{v^{2 / 3}}+\frac{18.01}{v^{6}}
$$

The guassian approximation is good enough in the frequency range of range of practical interest to evaluate the effect of misalignment and mismatches on coupling efficiency.

$$
L=-10 \log \left[\frac{16 n_{1}^{2} n_{3}^{2}}{\left(n_{1}+n_{3}\right)^{4}} \frac{4 \sigma}{q} e^{-\left(\frac{\rho u}{q}\right)}\right]
$$

Where

$$
\begin{aligned}
& \rho=\left(\mathrm{kw}_{1}\right)^{2} \\
& \mathrm{q}=\mathrm{G}^{2}+[\sigma+1]^{2} \\
& \mathrm{u}=(\sigma+1) \mathrm{F}^{2}+2 \sigma \mathrm{FG} \sin \theta+\sigma\left(\mathrm{G}^{2}+\sigma+1\right) \sin ^{2} \theta \\
& \mathrm{F}=\mathrm{d} /\left(\mathrm{kw}_{1}\right)^{2} \\
& \mathrm{G}=\mathrm{s} /\left(\mathrm{kw}_{1}\right)^{2} \\
& \sigma=\left(\mathrm{w}_{2} / \mathrm{w}_{1}\right)^{2} \\
& \mathrm{~K}=2 \pi \mathrm{n}_{3} / \lambda \\
& \mathrm{n}_{1}=\text { Refractive Index of Core } \\
& \mathrm{n}_{3}=\text { Refractive Index of medium between fibers. } \\
& \lambda=\text { Wavelength of Light Source } \\
& \mathrm{d}=\text { Transversal Offset } \\
& \mathrm{s}=\text { Longitudinal Offset. } \\
& \theta=\text { Angular Misalignment or tilt. } \\
& \mathrm{W}_{1}=1 / \mathrm{e} \text { mode field radius of transmitting fibers. } \\
& \mathrm{W}_{1}=1 \text { /e mode field radius of receiving fibers. }
\end{aligned}
$$

Equation (3.6) is general equation, which gives good approximation with experimental results and this equation is used to obtain the results for analysis. Similarly the equations for the different types of splicing losses ${ }^{10}$ are Transverse Offset

$$
\mathrm{L}_{\mathrm{t}}=-10 \log \operatorname{Exp}\left[-(\mathrm{d} / \mathrm{w})^{2}\right]
$$

Where $\mathrm{L}_{\mathrm{t}}=$ Transverse Offset loss $(\mathrm{dB})$

$\mathrm{d}=$ Transverse Offset $(\mu \mathrm{m})$

$\mathrm{w}=\mathrm{w}_{1}=\mathrm{w}_{2}$ is matching MFD $(\mu \mathrm{m})$

\section{Longitudinal Offset}

$$
L_{l}=-10 \log \left[1+16 s^{2} \lambda^{2} /\left(2 \pi n_{2} w\right)^{2}\right] \ldots
$$

Where $\mathrm{L}_{1}=$ Longitudinal Offset $(\mathrm{dB})$

$\mathrm{s}=$ Longitudinal Offset $(\mu \mathrm{m})$

$\lambda=$ Wavelength $(\mu \mathrm{m})$

$\mathrm{n}_{2}=$ Refractive Index of cladding $\mathrm{w}=\left(\mathrm{w}_{1}=\mathrm{w}_{2}=\mathrm{w}\right)$ is Matching MFD $(\mu \mathrm{m})$

Angular Misalignment or tilt

$$
\mathrm{L}_{\mathrm{a}}=10 \log \operatorname{Exp}\left[-\left(\pi \mathrm{n}_{2} \mathrm{w} \theta\right)^{2} / \lambda\right]
$$

Where $\mathrm{L}_{\mathrm{a}}=$ Angular Misalignment Loss $(\mathrm{dB})$

$\mathrm{n}_{2}=$ Refractive Index of Cladding

$\mathrm{w}=$ Matching MFD $(\mu \mathrm{m})$

$\theta=$ Tilt in radius

$\lambda=$ Wavelength $(\mu \mathrm{m})$

Mismatch Losses

$$
\mathrm{L}_{\mathrm{m}}=-10 \log \left[\left(2 \mathrm{w}_{1} \mathrm{w}_{2} / \mathrm{w}^{2}{ }_{1}+\mathrm{w}_{2}{ }_{2}\right)^{2}\right]
$$

Where $\mathrm{L}_{\mathrm{m}}=$ Mismatch Losses

$\mathrm{w}_{1}=$ MFD or Guassian spot size of fiber

$\mathrm{w}_{2}=$ MFD or Guassian spot size of fiber.

The Mode Field Diameter (MFD) is an important parameter related to the optical field distribution in the fiber. It has been shown that MFD provides useful information about the cabling performances ${ }^{8}$, such as possible joint, macro bending, micro bending losses and wave-guide Dispersion. The effective area of the fibers has a direct relation to the nonlinear distortions in long fiber links. Therefore, the MFD is an important parameter for characterizing SMF properties, which takes into account the wavelength dependent field penetration into the fiber cladding. Thus it is better to measure MFD than core diameter. MFD is generally taken as distance between the opposite $1 / \mathrm{e}=0.37$ field amplitude points and the power $1 / \mathrm{e}^{2}=.135$ points in relation to the corresponding values on the fiber axis.

Table 1: MFD AT $\Lambda=1.310$

\begin{tabular}{|c|c|c|c|}
\hline Fiber & $\begin{array}{c}\text { Effective } \\
\text { MFD } \\
\mu \mathrm{m}\end{array}$ & $\begin{array}{c}\text { Near Field } \\
(\text { Petermann-I) } \\
\mu \mathrm{m}\end{array}$ & $\begin{array}{c}\text { Far Field } \\
(\text { Petermann-II }) \\
\mu \mathrm{m}\end{array}$ \\
\hline DSF & 06.383300 & 11.393231 & 06.580070 \\
\hline DFF & 07.458293 & 08.178936 & 07.330303 \\
\hline
\end{tabular}

Table 2: MFD AT $\Lambda=1.55 \mathrm{MM}$

\begin{tabular}{|c|c|c|c|}
\hline Fiber & $\begin{array}{c}\text { Effective } \\
\text { MFD } \\
\mu \mathrm{m}\end{array}$ & $\begin{array}{c}\text { Near Field } \\
(\text { Petermann-I }) \\
\mu \mathrm{m}\end{array}$ & $\begin{array}{c}\text { Far Field } \\
(\text { Petermann-II }) \\
\mu \mathrm{m}\end{array}$ \\
\hline DSF & 08.250325 & 11.776263 & 08.460347 \\
\hline DFF & 08.750007 & 10.891704 & 08.653352 \\
\hline
\end{tabular}

\section{Analysis of Splice Loss}

The effect of a splicing error is computed as the transmission factor denoting the fraction of power coupled from one fiber to another fiber. This is done by taking the overlap integral between the model fields of the two fibers in presence of the splicing misalignments ${ }^{9}$. This integration carried out analytically in guassian approximation of the model fields and by using the expressions (3.5) and (3.6). The mode field diameter is calculated for the fibers.

The Effective MFD, near field diameter (Peterman I) and far field diameter (Peterman II) are calculated by using $M$. Artiglia et $\mathrm{al}^{4}$ and are given in Table 1 and 2 for the wavelength $\lambda=1.310 \mu \mathrm{m}$ and $\lambda=1.55 \mu \mathrm{m}$ respectively. These Tables 2 gives the MFD of fiber samples and shows 


\section{International Journal of Science and Research (IJSR) \\ ISSN (Online): 2319-7064}

Index Copernicus Value (2013): 6.14 | Impact Factor (2014): 5.611

that different fiber have different MFD according to the core size and profile design. The trade-off between effective area and MFD is an important deciding factor in selection of a design $^{12}$. Far field pattern ${ }^{5}$ is used for graded index fibers.

Table 3: Design of DSF

\begin{tabular}{|c|c|c|c|c|}
\hline \multirow[t]{2}{*}{ Region } & \multicolumn{2}{|c|}{ Diameter } & \multirow[t]{2}{*}{ Profile } & \multirow{2}{*}{$\begin{array}{c}\text { Refractive } \\
\text { Index }\end{array}$} \\
\hline & $\mathbf{a}$ & $\mathbf{2 a}$ & & \\
\hline $\begin{array}{c}\text { Region } 0 \\
\text { (Core) }\end{array}$ & $3.1 \mu \mathrm{m}$ & $6.2 \mu \mathrm{m}$ & $\begin{array}{c}\text { Linear Function } \\
\text { Start }=1.4615 \\
\text { End }=1.44692\end{array}$ & 1.4615 \\
\hline Region 1 & $1.32 \mu \mathrm{m}$ & $8.84 \mu \mathrm{m}$ & Constant & 1.44692 \\
\hline Region 2 & $1.5 \mu \mathrm{m}$ & $11.84 \mu \mathrm{m}$ & Constant & 1.45000 \\
\hline Region 3 & $57.3 \mu \mathrm{m}$ & 126.44 & Constant & 1.44692 \\
\hline \multicolumn{5}{|c|}{ Wavelength $=1300 \mathrm{~nm}$} \\
\hline \multicolumn{5}{|c|}{ Numerical Aperture $=0.183$} \\
\hline
\end{tabular}

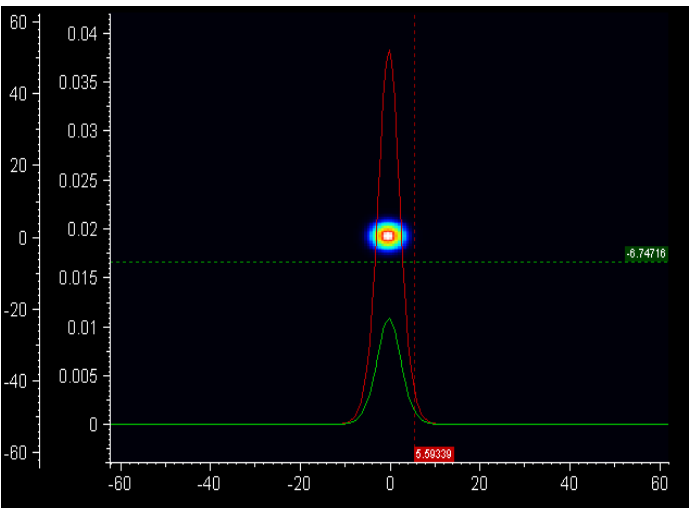

Figure 3: Profile of DSF

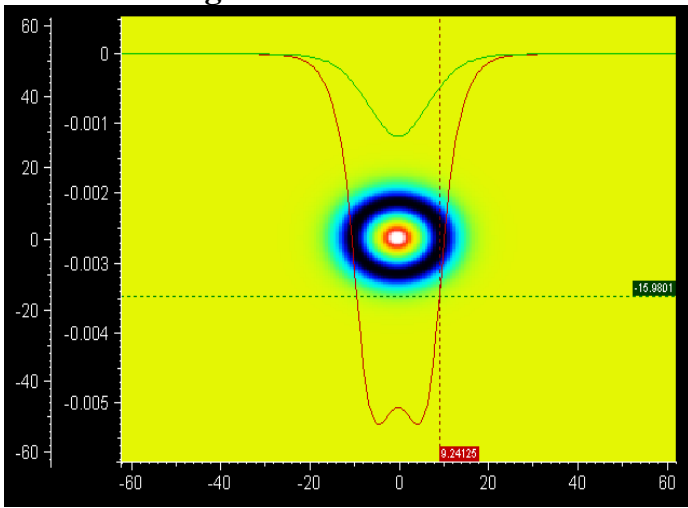

Figure 4: Profile of DFF

Table 4: Design of DFF

\begin{tabular}{|c|c|c|c|c|}
\hline Region & \multicolumn{2}{|c|}{ Diameter } & \multirow[t]{2}{*}{ Profile } & \multirow[t]{2}{*}{ Refractive Index } \\
\hline & $a$ & $2 a$ & & \\
\hline $\begin{array}{c}\text { Region } 0 \\
\text { (Core) }\end{array}$ & $4.2 \mu \mathrm{m}$ & $8.4 \mu \mathrm{m}$ & $\begin{array}{r}\text { Function } \\
(\mathrm{RI}+\Delta[1- \\
\left.(\mathrm{x} / \mathrm{w})^{\alpha}\right]\end{array}$ & $\begin{array}{c}\text { RI }=1.44370 \\
\text { Delta }(\Delta)=0.01 \\
\text { Alpha }(\alpha)=10 \\
\text { Steps }=20\end{array}$ \\
\hline $\begin{array}{c}\text { Region } 1 \\
\text { (Cladding) }\end{array}$ & $2.5 \mu \mathrm{m}$ & $13.4 \mu \mathrm{m}$ & Constant & 1.44370 \\
\hline $\begin{array}{c}\text { Region } 2 \\
\text { (Cladding) }\end{array}$ & $6.75 \mu \mathrm{m}$ & $26.90 \mu \mathrm{m}$ & $\begin{array}{c}\text { Function } \\
\text { RI }+\Delta[1- \\
((2 \mathrm{x}- \\
\left.\mathrm{w}) / \mathrm{w})^{\alpha}\right]\end{array}$ & $\begin{array}{c}\text { RI }=1.44692 \\
\text { Delta }(\Delta)=0.003 \\
\text { Alpha }(\alpha)=10 \\
\text { Steps }=20\end{array}$ \\
\hline $\begin{array}{c}\text { Region } 3 \\
\text { (Cladding) }\end{array}$ & $49.05 \mu \mathrm{m}$ & $125 \mu \mathrm{m}$ & Constant & 1.44370 \\
\hline \multicolumn{5}{|c|}{ Wavelength $=1300 \mathrm{~nm}$} \\
\hline \multicolumn{5}{|c|}{ Numerical Aperture $=0.0068$} \\
\hline Normalize & requency $=$ & 3.4357 & & \\
\hline
\end{tabular}

The splice loss increases with increase in transverse, Longitudinal, Angular misalignment or tilt and mismatching and the splice tolerances with respect to tilt and offset are mutually exclusive and the relationship has been the uncertainty principle ${ }^{3}$ also the offset and tilt are the important factor of splice or joint loss that is for low splice loss offset and tilt are to be of desirable considerations. The expressions for loss for small offsets and tilts are obtained by using the actual model field or appropriate spot size (MFD) of different fibers as given in Table 1 and 2. The Loss due to small offset is more accurately given by

$$
\mathrm{L}_{\mathrm{t}}=4.343(\mathrm{~d} / \mathrm{w})^{2}
$$

$\mathrm{L}_{\mathrm{t}}=$ Transverse Offset Loss

$\mathrm{d}=$ Offset in $\mu \mathrm{m}$

$\mathrm{w}=$ Peterman II spot size or for field MFD

Similarly - the loss due to small tilts is more accurately given by

$$
\mathrm{L}_{\mathrm{a}}=1.085\left(\mathrm{Kn}_{2} \mathrm{w}\right)^{2}
$$

$\mathrm{L}_{\mathrm{a}}=$ Angular or tilt loss

$\theta=$ Tilt in degree

$\mathrm{n}_{2}=$ Refractive index of cladding

$\mathrm{w}=$ Peterman-I spot size or Near field MFD

By using these equations the splice loses are calculated and shows the good agreement with theory. Typically acceptable splice loss is about $0.1 \mathrm{~dB}$. This means the maximum tolerable limit on the transverse offset is

$$
\mathrm{d}<0.152 \mathrm{w} \text { for } \mathrm{L}_{\mathrm{t}}<0.1 \mathrm{~dB}
$$

Thus larger the spot size larger is the offset that can be tolerated as shown in figure 7 similarly for tilt,

$$
\theta<0.304 /\left(\mathrm{Kn}_{2} \mathrm{~W}\right) \text { for } \mathrm{L}_{\mathrm{a}}<0.1 \mathrm{~dB}
$$

This shows that larger the spot size, smaller is the tilt that can be tolerated as shown in fig. 8 Thus for a fiber operating at $\lambda=1.310 \mu \mathrm{m}$ taken the form

$$
\theta<2.49 / \text { w degrees for } \mathrm{L}_{\mathrm{a}}<0.1 \mathrm{~dB}
$$

Thus the better tolerance to offset the modal field should be less confined, whereas for better tolerance to tilts, the mode field should be well confined. These mutually opposing trends have to be properly considered in design of single mode fiber ${ }^{13}$. The modes of single-mode fibers are very nearly gaussian in shape ${ }^{3}$ regardless of the fiber types that is step index or graded index. The splice losses are thus related to the corresponding losses of guasssian beam. The guided mode of weakly guiding fibers are very nearly transverse and linearly polarized the fibers used for experimental purpose has LP modes of all fibers. It is observed form figure 7 to 11 that the larger is the effective area of a fiber, the lower is the splice loss. This is explained by the fact that, where a fiber has a large effective area in electromagnetic fields are more spread throughout the cladding, resulting in less sensitivity to lateral misalignments ${ }^{11}$. The experimental values are in good agreement with theory and the result obtained agree with the exact results and the splice losses of 


\section{International Journal of Science and Research (IJSR) \\ ISSN (Online): 2319-7064}

Index Copernicus Value (2013): 6.14 | Impact Factor (2014): 5.611

all the fibers at $\lambda=1.31 \mu \mathrm{m}$ and $\lambda=1.55 \mu \mathrm{m}$ are as shown in Table 5 and 6 respectively.

Table 5: Splice Loss at $\Lambda=1.31 \mu \mathrm{m}$

\begin{tabular}{|c|c|c|c|c|c|}
\hline Fiber & $\begin{array}{c}\text { Total } \\
d B\end{array}$ & $\begin{array}{c}\text { Transversal } \\
d B\end{array}$ & $\begin{array}{c}\text { Longitudinal } \\
d B\end{array}$ & $\begin{array}{c}\text { Angular } \\
d B\end{array}$ & $\begin{array}{c}\text { Matching } \\
d B\end{array}$ \\
\hline DSF & 2.311347 & 0.499208 & 0.756078 & 0.879237 & 0.550915 \\
\hline DFF & 2.124196 & 0.968682 & 0.848901 & 0.448378 & 0.093131 \\
\hline
\end{tabular}

Table 6: Splice Loss at $\Lambda=1.55 \mu \mathrm{m}$

\begin{tabular}{|c|c|c|c|c|c|}
\hline Fiber & $\begin{array}{c}\text { Total } \\
d B\end{array}$ & $\begin{array}{c}\text { Transversal } \\
d B\end{array}$ & $\begin{array}{c}\text { Longitudinal } \\
d B\end{array}$ & $\begin{array}{c}\text { Angular } \\
d B\end{array}$ & $\begin{array}{c}\text { Matching } \\
d B\end{array}$ \\
\hline DSF & 2.369115 & 0.467263 & 0.758330 & 0.663509 & 0.714308 \\
\hline DFF & 2.069082 & 0.546239 & 0.757368 & 0.561652 & 0.361771 \\
\hline
\end{tabular}

\section{Results and Discussion}

The result shows that the Angular and Matching loss is maximum of Dispersion shifted fiber because its MFD (Peterman-I) is maximum as shown in Table 1 and figure 7 $(\mathrm{MFD}=11.39 \mu \mathrm{m}$ at $\lambda=1.310 \mu \mathrm{m})$ and is minimum of dispersion flattered fiber that is DFF because its MFD (Petermann-I) is minimum (MFD $=8.17 \mu \mathrm{m}$ at $\lambda=1.130$ $\mu \mathrm{m})$. This result shows the good agreement with D.Marcuse ${ }^{3}$ that wider fiber. From the calculation results it is observed that the total splice loss is maximum of DSF. Thus the single mode step index fiber is suitable for low splice loss. Also result shows that the Angular loss is maximum of Dispersion shifted fiber because it's MFD (Petermann-I) is maximum as shown in Table 1 and figure $7(\mathrm{MFD}=11.39 \mu \mathrm{m}$ at $\lambda=$ $1.310 \mu \mathrm{m})$ and is minimum of dispersion-flattered fiber because its MFD (Petermann-I) is minimum (MFD $=8.17$ $\mu \mathrm{m}$ at $\lambda=1.130 \mu \mathrm{m})$. This result shows the good agreement with D.Marcuse ${ }^{3}$ that wider fiber mode is less tolerant of angular misalignment.

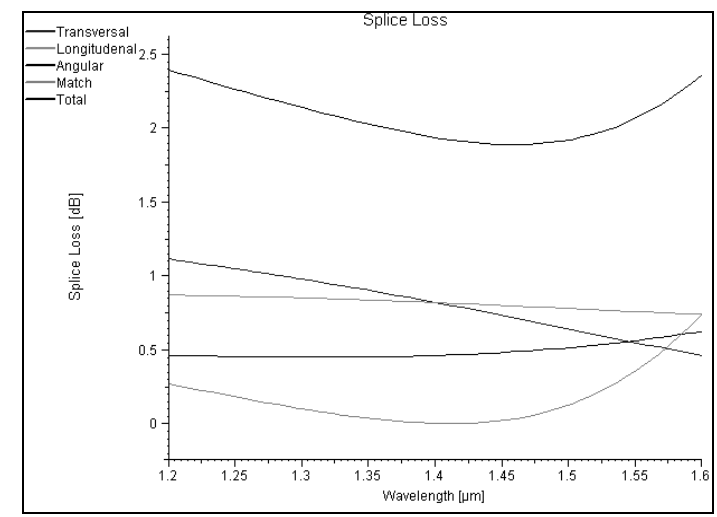

Figure 5: Splice Loss Vs Wavelength of Dispersion Shifted

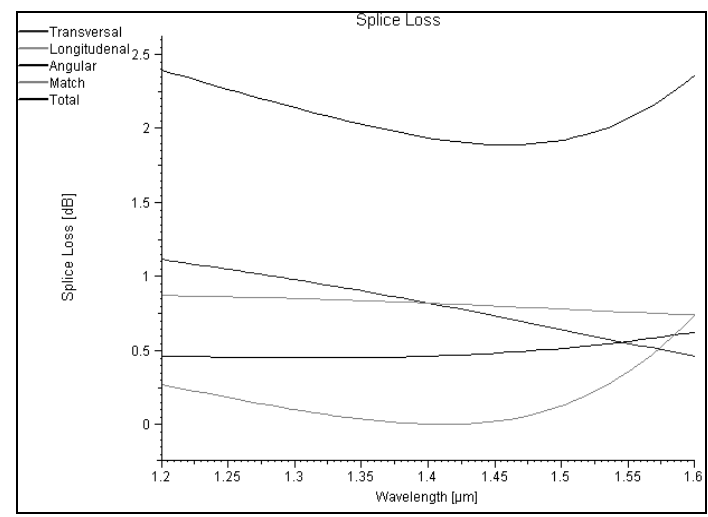

Figure 6: Splice Loss Vs Wavelength of Dispersion Flattened

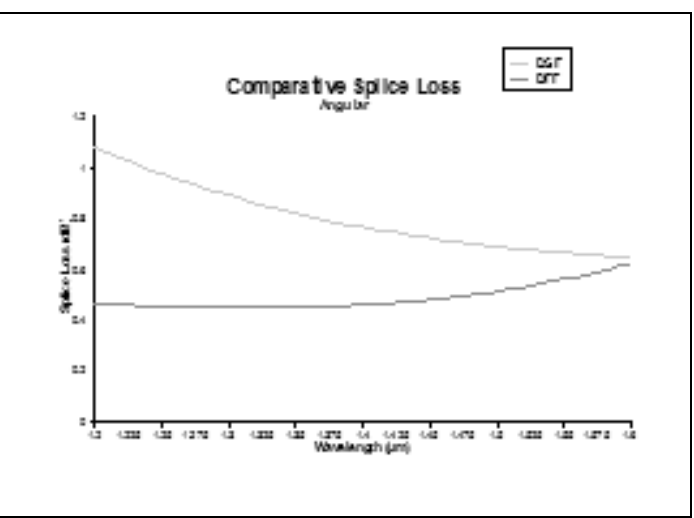

Figure 7: Comparative Angular SpliceLoss Vs Wavelength of Different fiber profile

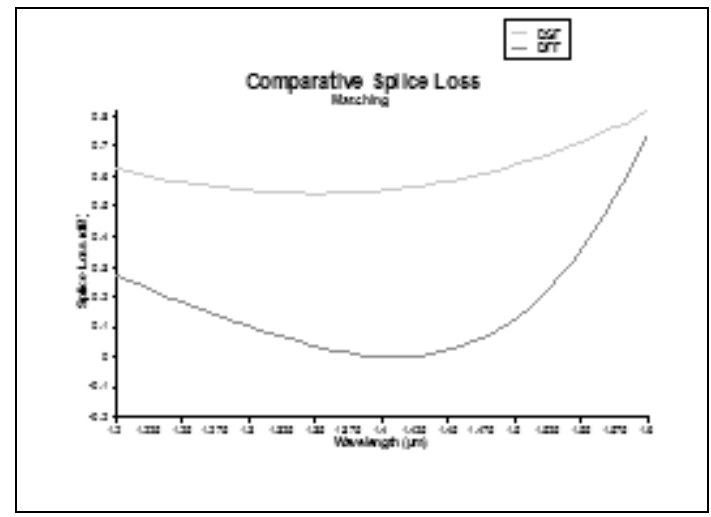

Figure 8: Comparative Matching Mode splice loss Vs wavelength of different fiber profile design 


\section{International Journal of Science and Research (IJSR) \\ ISSN (Online): 2319-7064}

Index Copernicus Value (2013): 6.14 | Impact Factor (2014): 5.611

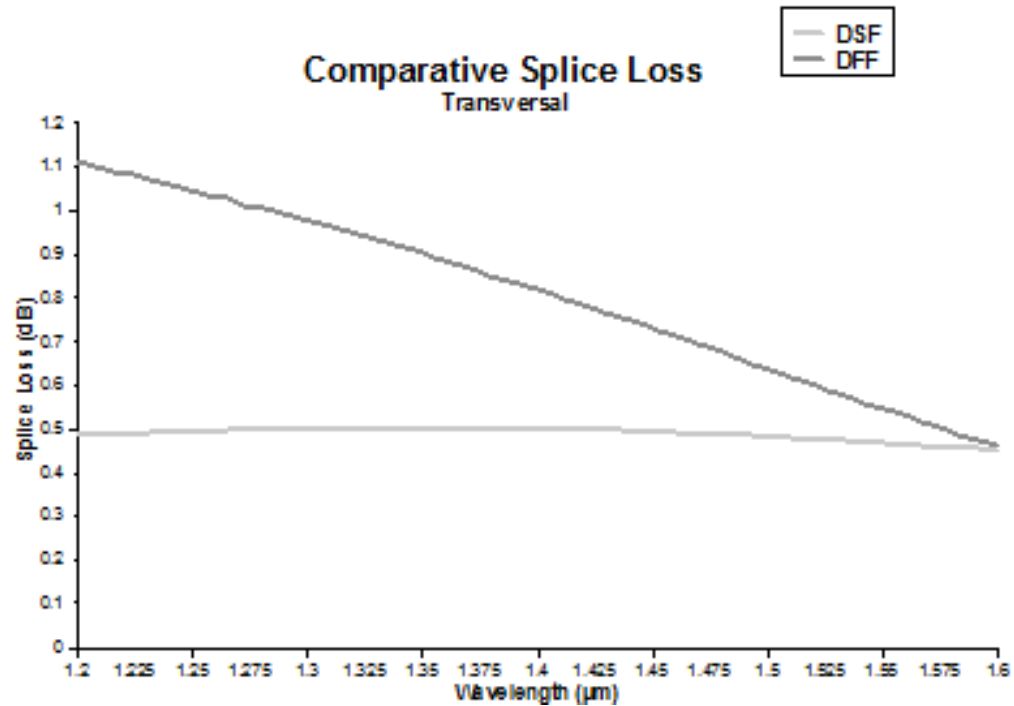

Figure 9: Comparative Transversal Splice loss Vs wavelength of Different fiber profile

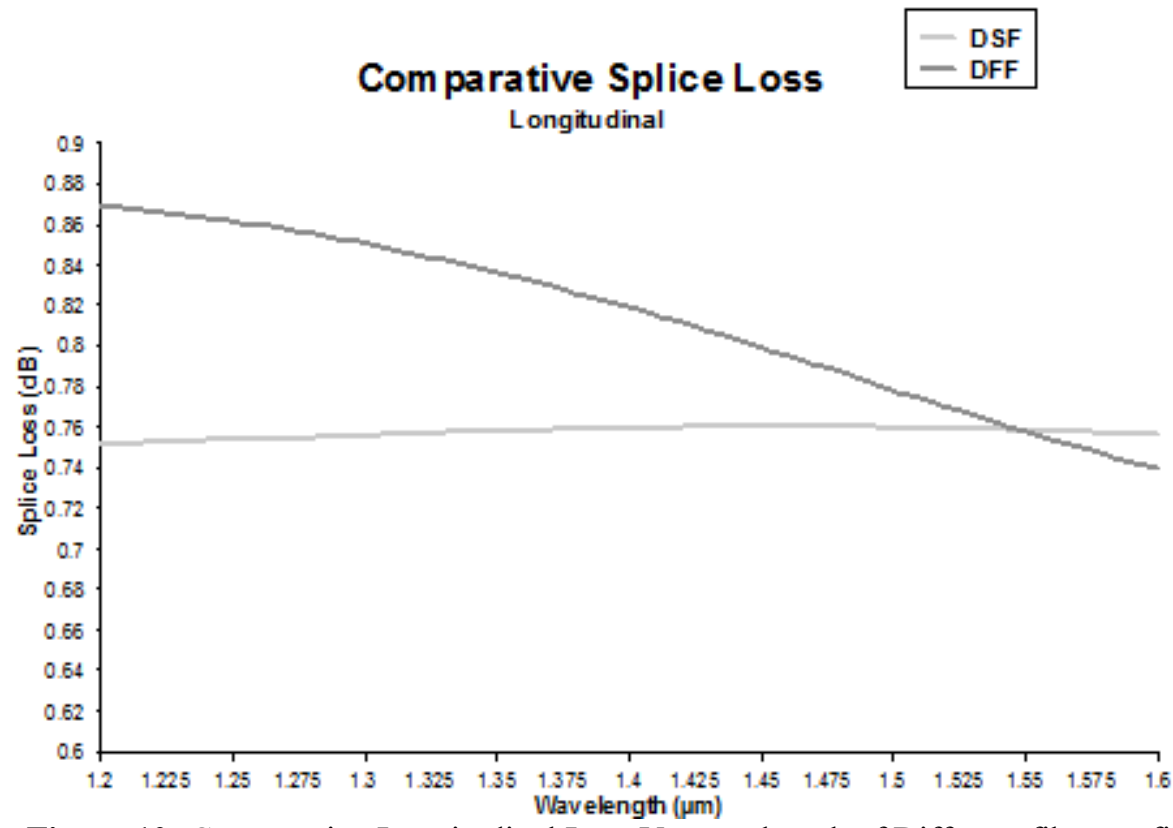

Figure 10: Comparative Longitudinal Loss Vs wavelength of Different fiber profile

\section{Conclusion}

The Splice losses have been minimum when the filed distribution is gaussian and in this case the two spot size parameters coincide. In all other cases splice losses are larger which directly gives $\mathrm{w}_{1} \leq \mathrm{w}_{2}$, where $\mathrm{w}_{1}$ and $\mathrm{w}_{2}$ are MFD of fiber 1 and 2 respectively and it is defined by K. Peterman et $\mathrm{al}^{6}$. The matching modes splice loss is maximum for DSF and is minimum of DFF, which is a Gaussian. Thus larger the mode field diameter leads to more matching splice loss and vice a versa. W.A. Gambling et $\mathrm{al}^{7}$ shows that the loss caused by offset and longitudinal is directly related to the field width at the fiber end also D. Marcuse ${ }^{3}$ states that, a fiber with a narrower width would be less tolerant of offset, splice loss and the experimental results from figure 11 and Table 4 and 5 shows that dispersion flattened fiber having MFD $=8.17 \mu \mathrm{m}$ gives maximum offset and longitudinal splice loss and dispersion shifted fiber having MFD $=11.39$ $\mu \mathrm{m}$ gives minimum offset loss. Thus the result obtained as shown in figure 11 are agree with theory and concluded that the individual losses are additive only when the defects are small the total loss depends on the relative directions of the tilt and plane of polarization that is transverse offset and thus offset and tilt are the major sources of splice loss. The jointing loss of single mode fibers is mainly dependent o their numerical aperture and mode filed diameter. It is concluded that the step index fiber has low splice losses than the other profile design.

\section{References}

[1] J.Sakai, "Splice Loss Evaluation for optical fibers with Arbitrary-Index Profile", Applied Optics,Vol. 17, No.17, pp 2848-2853,1978.

[2] D. Marcuse, "Gaussian approximation of the fundamental mode of Graded index fibers", J. Optical Society of America, Vol. 168, pp 103-109, Jan 1978.

[3] D. Marcuse, "Loss Analysis of single-mode fiber splices", The Bell system Technical journal Vol. 56, No. 5, May-Jun 1977.

[4] M. Artiglia, G. Coppa, P. DI Vita, M. Potenza and A. Sharma, "Mode field Diameter measurements in single- 


\section{International Journal of Science and Research (IJSR) \\ ISSN (Online): 2319-7064}

Index Copernicus Value (2013): 6.14 | Impact Factor (2014): 5.611

mode optical fibers", J. Of Light wave Technology vol. 7 No. 8 Aug 1989.

[5] N. Kashima, N. Uchida, N.Susa, S. Seikai, "The influence of a fiber structure on optical loss is a index fiber", Electronics letter 16th Feb. 1978, Vol. 14, No.4.

[6] K. Peterman R. Kuhne, "Upper and lower limits for the micro bending loss in arbitrary single mode fibers", J. Of Light wave Technology Vol. LT 4 No.1.

[7] W.A. Gambling, H. Matsumura, A.G. Cowley, "Jointing loss in single mode fibers", Electronics Letter 2nd Feb. 1978, Vol. 14, No. 3.

[8] K. Petermann, "Constraints for Fundamental-Mode Spot Size for Broadband Dispersion-Compensated SingleMode Fibres", Electronics Letters, 19, pp. 712-714, September 1983.

[9] S. N. Sarkar, E. K. Sharma, "Splice loss in Dispersionshifted and Dispersion- flattened single-Mode Fibers: A comparison", J. Of Optical Communications 7 (1986) 3, 101-103.

[10] D.Gloge, "Offset and Tilt loss in optical fiber Splices", The Bell system Technical Journal Vol. 55, No.7, Sep 1976.

[11] H. Hung-chia, W. Zi. Hua, "Analytical approach to prediction of Dispersion properties of step-index single mode optical fibers", Electronics Letter 5th march 1981 vol. 17 No. 5.

[12] Y. Akasaka, and Y. Suzuki, "Enlargement of Effective Core Area on Dispersion-Flattened Fiber and its Low Nonlinearity," OFC'98, San Jose, CA, paper ThK2, 1998.

[13] P. Nouchi, "Maximum Effective Area for Nonzero Dispersion-Shifted Fiber," OFC'98, San Jose, CA, paper ThK3, 1998. 